\title{
The distribution of mating-type bias in natural populations of the anther-smut Ustilago violacea on Silene alba in Virginia
}

\author{
P. V. Oudemans ${ }^{1}$ \\ H. M. Alexander \\ Departments of Botany, and Systematics and Ecology, \\ University of Kansas, Lawrence, Kansas 66045
}

J. Antonovics ${ }^{2}$

S. Altizer ${ }^{3}$

P. H. Thrall

L. Rose ${ }^{4}$

Department of Botany, Duke University, Durham, North Carolina 27708

\begin{abstract}
Complete individual-wide mating-type bias (retrieval of sporidia of only one mating type from germinated teliospores of one fungal individual) was observed to be a common and widespread feature of the anther-smut fungus, Ustilago violacea, collected from natural populations of its host, Silene alba. The bias was usually to mating type A1, but the frequency of bias and its spatial distribution varied from region to region. Populations with high frequencies of bias still showed high rates of disease transmission. Crosses between A1 mating type sporidial lines from completely biased individuals and A2 mating types from unbiased individuals showed no bias in the progeny. During teliospore germination, biased individuals often showed conjugation among adjacent cells of the promycelium, suggesting that both mating types are present in the germinating teliospore but one mating type is unable to grow as free-living sporidia. The complete bias was most readily interpreted as evidence of "haploid lethals" linked to mating type that cause poor survival or growth of the sporidial stage. The results show that such "haploid lethals" may be a common occurrence in natural populations, and that fungal mating systems may vary considerably over short distances.
\end{abstract}

Key Words: disease epidemiology, haplolethal deficiency, intrapromycelial conjugation, mating sys-

Accepted for publication November 10, 1997.

${ }^{1}$ Current address: Rutgers Blueberry and Cranberry Research Center, Lake Oswego Rd., Chatsworth, New Jersey 08019.

${ }^{2}$ Corresponding author, email: danton@duke.edu

${ }^{3}$ Current address: Department of Ecology, Evolution and Behavior, University of Minnesota, St. Paul, Minnesota 55108.

${ }^{4}$ Current address: Section of Evolution and Ecology, University of California, Davis, California 95616. tem, Microbotryum violaceum, Silene latifolia, solopathogenicity, teliospore germination, Ustilaginales

\section{INTRODUCTION}

The anther-smut fungus Ustilago violacea (Pers.) Fuckel (= Microbotryum violaceum Deml \& Oberwinkler) is a basidiomycete in the order Ustilaginales (Deml and Oberwinkler, 1983). It is a pathogen of many species in the Caryophyllaceae (Thrall et al., 1993), including Silene alba (Miller) Krause (=S. latifolia Poiret), a common roadside weed in eastern North America. Teliospores are usually transmitted from diseased to healthy hosts by insect pollinators (Antonovics and Alexander, 1992; Shykoff and Bucheli, 1995; Roche et al., 1995; Altizer et al., 1998). Once the teliospores have been deposited onto a flower or leaf surface (the most frequent route of infection is unknown), they germinate and undergo meiosis to produce a promycelium. This promycelium is usually three-celled and each promycelial cell and the teliospore itself then buds off one or more sporidia, which multiply mitotically by budding. These sporidia are of two mating types, A1 and A2, which conjugate to form an infective dikaryotic hypha that invades and eventually spreads throughout the host plant (Cummins and Day, 1977). When an infected plant flowers, the mycelium enters the developing anthers, undergoes karyogamy, and differentiates to produce large numbers of diploid teliospores (Batcho and Audran, 1980).

As part of a study of the occurrence of diseased and healthy S. alba in Giles Co., Virginia (Antonovics et al., 1994; Thrall and Antonovics, 1995), teliospores from diseased flowers were collected in several populations. During isolation of haploid sporidia from germinating teliospores, instances were found where sporidia of only the A1 mating type were recovered. This absence of the A2 sporidia was expressed in all teliospores sampled from a single flower and on a range of culture media (potato dextrose agar, yeast glucose agar, or water agar). It was confirmed by independent studies in two laboratories (University of Kansas and Duke University) as well as by tests on these lines carried out by E. D. Garber (University of Chicago, pers. comm.). This phenomenon is particularly interesting because it has generally been con- 
sidered that fusion of opposite mating types is a prerequisite for dikaryon formation and infectivity of $U$. violacea (Cummins and Day, 1977) and of most other smut fungi (Fischer and Holton, 1957); the absence of sporidia of one mating type might be expected to have severe consequences for fungal pathogenicity. Similar deficiencies of sporidia of one mating type have been observed in other Ustilaginales (Holton, 1951; Grasso, 1955), and have been explained as the result of mutations which result in loss of viability in the haploid phase ("haplolethal deficiencies") but which may have compensatory advantages in the diploid pathogenic phase. However, there have been no detailed studies on the frequency, spatial distribution, and population consequences of such deficiencies in naturally occurring populations of smut fungi. The objectives in this study were therefore to describe the spatial distribution of the bias both within and among naturally occurring populations, and to confirm the haplolethal nature of the bias using crosses between biased and unbiased lines, and observations of teliospore germination.

Note on terminology.-Teliospores collected from a single flower are likely to be the products of one diploid fungal genotype (Day, 1980). Because these teliospores undergo meiosis to produce sporidia that are themselves different haploid genotypes, we use the term "fungal individual" to refer to the fungal genotype that produces the teliospores in one diseased flower. The sporidia produced by the promycelium can themselves multiply mitotically, and hence sporidial progeny isolated from a culture started from a single teliospore will sometimes be identical genotypes, at other times different genotypes; we, therefore, use the neutral term "single sporidial line" to refer to the mitotic derivatives of a single haploid sporidial isolate.

We use the term "single-teliospore bias" to refer to mating-type bias among the products of a single teliospore. We use the term "individual-wide bias" when all the teliospores produced by one fungal individual show an average bias towards one mating type.

We use the term "complete" bias where singlesporidial lines isolated from the teliospores were all of the same mating type. We inferred the presence of complete bias if at least ten sporidial lines were of only one mating type. In the case of "complete single-teliospore bias", these ten lines would be from one teliospore; in the case of "complete individualwide bias" each of these sporidial lines would be from ten separate teliospores. Assuming the frequency of individual-wide bias in a population is ca $50 \%$ (close to what was inferred ex post facto, see results) and assuming the bias will always be towards one mating type (as was also generally found), a sample size of ten gives a misclassification probability of 0.00098 (Alexander et al., 1995). We use the term "partial bias" for situations where both mating types were present but where there was a statistically significant deviation from 1:1 expectation (see results for statistical tests). However, in the absence of any a priori expectation of the degree of partial bias, we did not explicitly categorize individuals as either "partially biased" or "unbiased".

\section{MATERIALS AND METHODS}

Collection of spores. - Teliospore collections were made independently by two laboratories (at Kansas and Duke), initially for studies unrelated to the mating-type bias. The collections were made in an area (approx $25 \times 25 \mathrm{~km}$ ) centered around Mountain Lake Biological Station, Giles County, Virginia, where the disease and its host have been intensively studied since 1988 in mapped roadside locations (Antonovics et al., 1994; Thrall and Antonovics, 1995; McCauley, 1994). Diseased flowers were sampled from plants growing in $40 \mathrm{~m}$ linear segments of roadway (marked separately for each side of the road) that had been defined as part of the above studies.

For the studies at Kansas, in 1992, a total of 182 diseased plants were sampled from five regions of the study area. Additionally, diseased plants were sampled from one population near the Blue Ridge Parkway, Floyd Co., Virginia (see TABle I). One flower was collected from each diseased plant, and flowers were stored individually in $1.5-\mathrm{ml}$ microcentrifuge tubes filled with Drierite (dehydrated calcium sulphate). In 1993, a more detailed sampling of 70 flowers was carried out on a single section of the study area (Section 6.1h) which spanned approximately $700 \mathrm{~m}$ of roadway; the coordinates of each collected flower were recorded so that a spatial map could be constructed of the locations of each infected plant.

For the studies at Duke, a total of 25 diseased plants were sampled from the study area in 1991 and 1992. Sampling was done by inserting a Q-tip (a small cotton swab on a stick) into one diseased flower per plant so that it became smothered in spores; each Qtip was stored over Drierite in a small screw-cap vial.

Detection of the mating-type bias. - Mating type was determined by mixing small quantities of each single sporidial line with standard isolates of each mating type on water agar plates, and examining the mixtures microscopically for conjugating sporidia. Thus, for example, conjugation with an A2 standard 
TABle I. Percentage of individuals with complete A1 mating-type bias in $U$. violacea collected from different regions of Virginia in 1992, and tested at the University of Kansas using ca 20 single sporidial lines. Each individual was sampled as a teliospore collection from a single flower on a single diseased plant. Section numbers refer to regions of the long-term metapopulation study (Thrall and Antonovics, 1995). Sections 1.1f, 2.1a, and 2.1c are arranged more or less linearly in the same valley; these are separated from section $5.1 \mathrm{a}, \mathrm{b}$ by $10 \mathrm{~km}$, and $5.1 \mathrm{a}, \mathrm{b}$ is $6 \mathrm{~km}$ from $6.1 \mathrm{~h}$. These are all separated from the Blue Ridge Parkway site by ca $60 \mathrm{~km}$

\begin{tabular}{|c|c|c|c|c|c|}
\hline Location & Section & $\begin{array}{l}\text { Num- } \\
\text { ber } \\
\text { of } \\
\text { host } \\
\text { plants }\end{array}$ & $\begin{array}{l}\% \text { host } \\
\text { plants } \\
\text { dis- } \\
\text { eased }\end{array}$ & $\begin{array}{l}\text { Num- } \\
\text { ber } \\
\text { of } \\
\text { collec- } \\
\text { tions } \\
\text { tested } \\
\text { for } \\
\text { bias }\end{array}$ & $\begin{array}{c}\% \\
\text { com- } \\
\text { plete } \\
\text { bias }^{\mathrm{a}}\end{array}$ \\
\hline \multicolumn{6}{|l|}{ Giles County } \\
\hline Rt 635 & $1.1 \mathrm{f}$ & 268 & 29.4 & 64 & 15.6 \\
\hline Rt 635 & $2.1 \mathrm{a}$ & 260 & 11.9 & 21 & 19.0 \\
\hline Rt 684 & $2.1 \mathrm{c}$ & 645 & 12.5 & 56 & 98.2 \\
\hline Rt 700 & $5.1 \mathrm{a}, \mathrm{b}$ & 300 & 15.3 & 25 & 8.0 \\
\hline Rt 601 & $6.1 \mathrm{~h}$ & 381 & 20.2 & 70 & 72.9 \\
\hline Floyd County & & - & - & 16 & 0 \\
\hline
\end{tabular}

a Significance of among population differences in bias: $\chi^{2}$ $=75.84, \mathrm{df}=5, P<0.0001$.

and failure to conjugate with an A1 standard indicated that the sporidial line was A1.

For the collections studied at Kansas, individual wide bias was determined as follows. Single sporidial lines were obtained from each fungal genotype using a method similar to random sporidial analysis used in genetic studies (Day and Jones, 1969). Two to three spore-laden anthers were placed in $5 \mathrm{~mL}$ of sterile distilled water $\left(\mathrm{sdH}_{2} \mathrm{O}\right)$ and crushed to release the teliospores. The teliospore suspension was serially diluted, spread-plated on to YAG medium ( $5 \mathrm{~g}$ yeast extract, $20 \mathrm{~g}$ glucose, $20 \mathrm{~g}$ agar per $\mathrm{L}$ ) and incubated at room temperature for $48 \mathrm{~h}$ to allow for teliospore germination. The plates were then washed with $2 \mathrm{~mL}$ $\mathrm{sdH}_{2} 0$ to recover the sporidia, the washings were serially diluted, and spread-plated onto YAG plates. After one wk, single sporidial colonies were visible. Using sterile toothpicks, 20 colonies from each fungal genotype were transferred onto YAG plates and maintained as single sporidial lines. These were incubated at room temperature until the colonies were approximately 7-10 $\mathrm{mm}$ diam, at which time mating type was determined using line $6(=\mathrm{A} 1)$, and line 9 (=A2) (from Alexander, 1989) as standards. Conjugations were carried out 2\% Difco Bacto agar plates which were incubated at $4 \mathrm{C}$ for at least one wk, and examined for conjugating sporidia.

Observations of sporidial conjugation in germinating teliospore suspensions were also used to detect complete individual-wide mating-type bias. An aliquot (ca $4 \mathrm{~mL}$ ) of the original teliospore suspension was placed in a drum rotor and incubated at $15 \mathrm{C}$ for 48-72 $\mathrm{h}$. The resulting sporidial suspension was then examined microscopically for the presence of sporidial conjugation, indicating the presence of both mating types. This technique is faster in that prior culture of sporidial lines is unnecessary, but has the disadvantage that the direction of bias and the frequency of the two mating types cannot be determined. Initial studies confirmed that the results using this second method were completely concordant with studies using sporidial lines.

At Duke, studies of single-teliospore bias were carried out as follows. Smut samples were shaken onto potato dextrose agar (PDA) plates to generate colonies of sporidia, each colony being produced by a single germinating teliospore. Three colonies were picked off, diluted in $1 \mathrm{~mL}$ water, and spread onto a PDA plate. Up to 20 single sporidial lines from each teliospore colony were then dotted onto one plate to get a "library" of cultures. These were later transferred to water agar plates and mixed with standard $\mathrm{A} 1$ or A2 types (lines 31 and 36, from isolates of Alexander, 1989) for at least $24 \mathrm{~h}$ at $12 \mathrm{C}$ and scored for conjugation.

Test for solopathogenicity. - To test the hypothesis that sporidial lines isolated from biased collections could be pathogenic without prior mating (perhaps because they were diploid or aneuploid; Caten and Day, 1977), plants were inoculated at Duke with Al sporidial lines derived from fungal individuals showing complete bias. Twelve such lines from a variety of locations in the study area were each inoculated onto 21 healthy host plants in the rosette stage. As controls, these same 12 lines were mated with A2 lines from a variety of unbiased teliospore collections, and each mating was used to inoculate 14 healthy host plants. Host plants came from a bulk sample of seeds from several populations in the study area.

For the inoculations, loopfuls of sporidia of appropriate mating types were mixed and suspended in $\mathrm{sdH}_{2} \mathrm{O}$ to produce a milky suspension (ca $10^{6}$ sporidia per $\mathrm{mL}$ ), and $30 \mu \mathrm{L}$ of single sporidial lines, or $15+15 \mu \mathrm{L}$ of the mixed lines were used to inoculate young plants at the rosette stage (ca 5-10 leaves) by piercing axils of leaves with a needle while drops of the culture were placed on the wounds. Plants were kept in the lab and away from watering for two days, and then transferred to the greenhouse. They were 
transplanted to 20-cm pots in April 1992 and kept outside at Mountain Lake Biological Station, Virginia, where they were scored for flowering and disease that summer.

Inheritance of mating-type bias.-To assess whether the mating-type bias was heritable, the occurrence of mating-type bias was investigated in the teliospores produced by crosses between biased A1 lines and unbiased A2 lines.

At Kansas, crosses were performed using A1 single sporidial lines from five unbiased individuals and $\mathrm{Al}$ lines from five biased individuals. These were crossed to five A2 lines (from unbiased individuals), but in an incomplete design to give 12 crosses involving biased $\mathrm{A} 1$ lines, and 10 involving unbiased $\mathrm{A} 1$ lines. Crosses were carried out as follows. The single sporidial lines were sub-cultured on YAG medium at 20 C for 9-10 da. Approximately equal quantities of opposite mating type were mixed together on water agar plates for $48 \mathrm{~h}$ at $4 \mathrm{C}$ to induce conjugation. Seeds were planted in sterile sand and grown till the plants were approximately $2 \mathrm{~cm}$ tall. Seedlings were then inoculated by placing them directly in the sporidial mixtures on the water agar plates and incubating them at $20 \mathrm{C}$ for $24 \mathrm{~h}$. Five seedlings per sporidial combination were generally used. Seedlings were then planted in a standard potting mix and placed in growth chambers at $20 \mathrm{C}$ and $16 \mathrm{~h}$ photoperiod. Flowering began two mo after planting and matingtype ratios were determined on individual sporidial lines derived from teliospore collections.

At Duke, teliospores were sampled from 5 of the 12 crosses between A1 biased and A2 unbiased lines of the solopathogenicity study. Mating type was determined on a sample of ca 20 single sporidial lines from three teliospores from each infected plant.

Plants that became diseased following inoculation with these crosses were then used as a disease source in a field experiment (Thrall and Antonovics, 1995). Disease spread occurred naturally in this experiment, and, therefore, while the precise parentage of new infections could not be determined in the absence of suitable genetic markers, these new infections were almost certainly the progeny of the diseased source plants because experiment was carried out in an isolated grazed field. Teliospores sampled from single flowers of seven of these newly diseased plants were then tested for the presence of mating-type bias.

Teliospore germination.-To investigate the process of teliospore germination, aliquots of the concentrated teliospore suspensions from the Kansas collections were spread plated on $1.5 \%$ water agar plates and incubated at $15 \mathrm{C}$. After $24 \mathrm{~h}$ a small rectangle of media was removed from each plate, and placed on a microscope slide to which a cover slip was carefully applied. Individual teliospore colonies were observed for mating events. To examine whether the different types of teliospore germination events resulted in the production of an infection hyphae, the microscopic observations were also made after addition of $10^{-5} \mathrm{M}$ alpha-tocopherol to the medium; this elicits the production of infection hyphae from conjugating sporidia (Castle and Day, 1984).

Statistical analyses.-All statistical analyses were carried out using Statistical Analysis System for Windows (SAS Institute, Cary, North Carolina). Tests on mating type frequencies were carried out using log-linear models in the CATMOD procedure. Regression analyses were carried out using the GLM procedure.

\section{RESULTS}

Frequency and distribution of mating-type bias.-Of 252 fungal individuals tested using single sporidial lines at Kansas (TABLE I), complete Al bias was observed in 127, while complete A2 bias was observed in three. There were highly significant differences among the six regions sampled in the proportions of fungal individuals showing complete A1 bias (TABLE I). Of the 25 collections tested at Duke, 7 showed complete A1 bias. Sites determined to be heavily biased by the Kansas group (Sections 2.1c and 6.1h), were also biased when tested by the Duke methods. Similarly, at the site determined to be largely unbiased by the Kansas group (Section 5.1a), all of the 11 fungal individuals studied by the Duke group were unbiased.

At Duke, many single sporidial lines were obtained from each of several teliospores obtained from a single diseased flower. In the completely biased lines (by definition) all sporidial lines from all teliospores of one fungal individual were only of one mating type. However, even in individuals that segregated both mating types, single-teliospore bias was common, but the direction of this bias differed among teliospores derived from a single individual (TABLE II). Among all samples, there was an overall partial bias $(56.4 \%)$ in favor of A2 that was highly significant $\left(\chi^{2}=7.19\right.$, degrees of freedom $=1, P=0.0073$ ).

In three of the regions where complete individualwide bias was observed, diseased plants occurred in several contiguous $40 \mathrm{~m}$ roadside segments, so that it was possible to examine the spatial distribution of the bias. In Section 1.1f, where relatively few individuals were completely biased (TABLE I), there was a clinal distribution of the frequency of the two mating types among the sampled individuals (FIG. 1A). At one end of this Section (segments 0.350 and 0.375 ) there was a predominance of $\mathrm{A} 1$, including a number 
TABLE II. Numbers of two mating types (A1 and A2) among sporidial lines isolated from each of several teliospores from individuals of $U$. violacea collected from single flowers of diseased hosts in various locations in Giles County, Virginia, and tested at Duke University. Locations refer to section number and roadside segment of the long-term metapopulation study (Thrall and Antonovics, 1995). " $P$, overall" tests for deviation from 1:1 mating-type segregation in all teliospores sampled from one individual (overall bias); " $P$, interaction" tests whether there is heterogeneity among teliospores in the observed mating-type segregation ratio (i.e., heterogeneity in single teliospore bias)

\begin{tabular}{|c|c|c|c|c|c|}
\hline $\begin{array}{c}\text { Location } \\
\text { of } \\
\text { individual }\end{array}$ & $\begin{array}{l}\text { Telio- } \\
\text { spore }\end{array}$ & $\begin{array}{c}\text { Number } \\
\text { of Al } \\
\text { lines }\end{array}$ & $\begin{array}{c}\text { Number } \\
\text { of A2 } \\
\text { lines }\end{array}$ & $\begin{array}{c}P, \\
\text { overall }\end{array}$ & $\begin{array}{c}P, \\
\text { inter- } \\
\text { action }\end{array}$ \\
\hline \multirow[t]{2}{*}{$1.1 \mathrm{e}-3.525$} & 1 & 1 & 19 & $0.001 * * * a$ & $0.036^{*}$ \\
\hline & 2 & 8 & 13 & & \\
\hline \multirow{3}{*}{$5.1 \mathrm{a}-1.750$} & 1 & 6 & 14 & 0.233 & 0.287 \\
\hline & 2 & 11 & 9 & & \\
\hline & 3 & 8 & 11 & & \\
\hline \multirow[t]{3}{*}{$5.1 \mathrm{a}-2.175$} & 1 & 8 & 9 & 0.695 & 0.953 \\
\hline & 2 & 9 & 11 & & \\
\hline & 3 & 9 & 9 & & \\
\hline \multirow[t]{3}{*}{$6.1 \mathrm{~d}-0.025$} & 1 & 8 & 5 & $0.004^{* *}$ & $0.007 * *$ \\
\hline & 2 & 3 & 14 & & \\
\hline & 3 & 2 & 18 & & \\
\hline \multirow{3}{*}{$6.1 \mathrm{e}-2.150$} & 1 & 3 & 15 & $0.003 * *$ & $0.032^{*}$ \\
\hline & 2 & 9 & 8 & & \\
\hline & 3 & 2 & 12 & & \\
\hline \multirow[t]{3}{*}{$6.1 \mathrm{e}-2.150$} & 1 & 11 & 8 & $0.003 * *$ & 0.083 \\
\hline & 2 & 11 & 7 & & \\
\hline & 3 & 18 & 2 & & \\
\hline \multirow[t]{3}{*}{$6.1 \mathrm{e}-2.150$} & 1 & 18 & 2 & 0.154 & $0.004^{* *}$ \\
\hline & 2 & 6 & 13 & & \\
\hline & 3 & 1 & 10 & & \\
\hline \multirow[t]{2}{*}{$8.1 c-0.675$} & 1 & 7 & 17 & 0.092 & 0.346 \\
\hline & 2 & 7 & 9 & & \\
\hline \multirow[t]{3}{*}{$8.1 c-0.675$} & 1 & 12 & 9 & 0.926 & 0.331 \\
\hline & 2 & 8 & 14 & & \\
\hline & 3 & 11 & 9 & & \\
\hline
\end{tabular}

a Significance: $*=P<0.05, * *=P<0.01, * * *=P<$ 0.001 .

of individuals fixed for A1. At the other end (segments 0.400 and 0.425 ) there was a preponderance of individuals with an A2 bias, including two individuals fixed for A2. We could also show that the number of individuals that were observed with complete bias would not be expected simply as statistical extremes of the overall partial bias towards either $\mathrm{Al}$ or A2 in these segments. Thus in the segments with a preponderance of $\mathrm{Al}$, there was still a partial matingtype bias $\left(58.6 \%: \chi^{2}=8.82, \mathrm{df}=1, P=0.003\right)$ but no significant among plant heterogeneity $\left(\chi^{2}=\right.$ $20.62, \mathrm{df}=14, P=0.112$ ) if the 8 completely biased individuals and one individual where 19/20 telio- spores were all A1 were excluded. However, if these biased individuals were included in the analysis, there were significant differences in the degree of bias among fungal individuals $\left(\chi^{2}=74.17, \mathrm{df}=23, P<\right.$ $0.001)$. Similarly, in the adjacent segments with a preponderance of $\mathrm{A} 2$, when the three individuals with complete bias (one A1 and two A2) were excluded from the analysis, there was an overall partial bias to A2 (57.8\%: $\left.\chi^{2}=10.68, \mathrm{df}=1, P=0.001\right)$ but no differences among the individuals $\left(\chi^{2}=20.92, \mathrm{df}=\right.$ $17, P=0.230)$. However, when the two lines with A2 bias were included in the analysis, the heterogeneity became significant $\left(\chi^{2}=34.77, \mathrm{df}=19, P=0.015\right)$.

In Section 5 (FIG. 1B), there were only two completely biased individuals (one $\mathrm{Al}$ and one A2). When these completely biased individuals were excluded from the analysis, there was a significant overall partial bias towards Al (60.1\%: $\chi^{2}=23.96, \mathrm{df}=$ $1, P<0.001)$. There was also significant heterogeneity in the partial bias among fungal individuals $\left(\chi^{2}\right.$ $=35.38, \mathrm{df}=22, P=0.0350$ ). If the two completely biased individuals were included in the analysis, there was still a significant bias towards Al $\left(\chi^{2}=5.03\right.$, df $=1, P=0.0250)$ and the significance of the heterogeneity increased substantially $\left(\chi^{2}=41.00, \mathrm{df}=24\right.$, $P=0.0167)$. The degree of partial bias showed no significant relationship with distance; nor was there any significant heterogeneity among the roadside segments in the degree of partial bias.

In Section $6.1 \mathrm{~h}$, where a large number of fungal individuals showed complete A1 bias (TABL.F. I), the incidence of completely biased individuals was highly clumped (FIG. 1C). If the completely biased individuals were excluded from the analysis, there was no significant partial bias $\left(\chi^{2}=0.13, \mathrm{df}=1, P=0.715\right)$, but the individual by mating-type frequency interaction approached significance $\left(\chi^{2}=28.42, \mathrm{df}=18, P\right.$ $=0.056)$. However, if one extremely biased individual was excluded from the analysis (this individual had $11 \mathrm{~A} 1$ sporidial lines and one line that conjugated with both $\mathrm{Al}$ and A2), the individual by matingtype frequency interaction was no longer significant $\left(\chi^{2}=21.66, \mathrm{df}=17, P=0.198\right)$, but there was now a significant overall partial bias $(56.6 \%)$ towards A2 $\left(\chi^{2}=5.50, \mathrm{df}=1, P=0.019\right)$.

Correlations between mating-type bias and disease dynamics. - The area from which the teliospore collections were sampled has been part of a long term study of S. alba and $U$. violacea (Antonovics et al., 1994; Thrall and Antonovics, 1995). Therefore, we investigated whether the presence of bias was correlated with disease dynamics in each of the $40 \mathrm{~m}$ roadside segments from which teliospores had been collected for bias testing. Two components of disease 


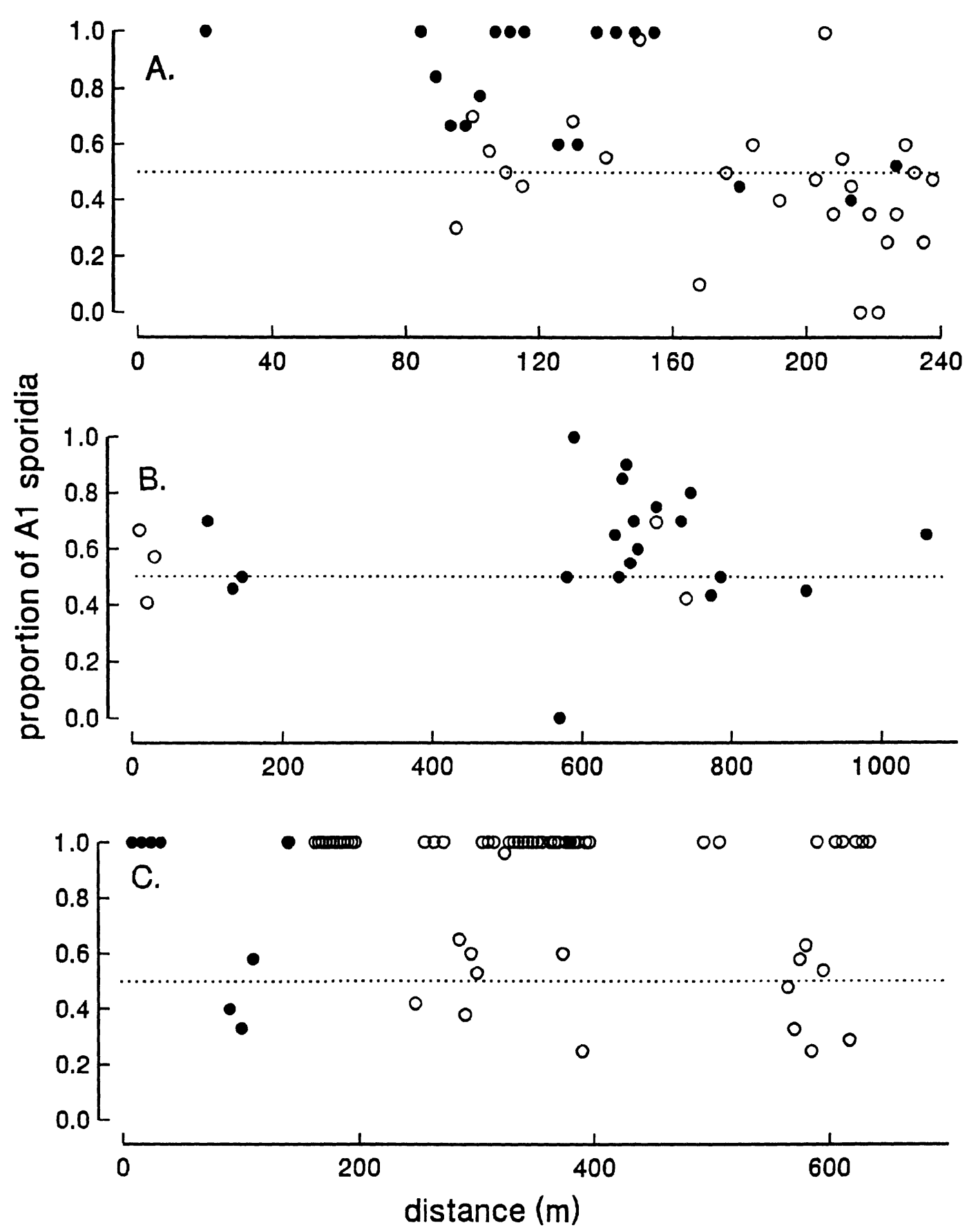

FIG. 1. Relationship between frequency of mating type A1 and roadside position. A. Section 1.1f, starting at roadside segment 0.30 ; B. Section 5.1a,b starting at roadside segment 1.70 ; and C. Section $6.1 \mathrm{~h}$, starting at roadside segment 0.15 . Each point shows the frequency of A1 in c. 20 single-sporidial lines from a single fungal individual. Solid and open circles represent samples from the left and right hand sides of the road, respectively. Note: Sections are marked as in the long-term metapopulation study (Thrall and Antonovics, 1995); scale on the x-axis varies among sections. In Section $6.1 \mathrm{~h}$, the positions are placed by direct mapping; in other sections, the individuals were identified only as to segment, and for graphical purposes have been plotted at even spacing within each segment.

dynamics were estimated. First, we calculated the difference between disease frequency in the year when the fungal samples were collected and the frequency of disease in the subsequent year. Second, we estimated the disease transmission coefficient using the relationship $y_{t+1} / y_{t}=\left(1+\beta x_{t} /\left(x_{t}+y_{t}\right)\right)(1-d)$, where $y_{t}$ and $y_{t+1}=$ number of diseased individuals at time $t$ and $t+1$ respectively, $x_{t}=$ number of healthy individuals at time $t, d=$ death rate, and $\beta=$ disease transmission coefficient (for discussion of models of 
the Ustilago-Silene system see Antonovics, 1994; Thrall et al., 1994; Thrall and Jarosz, 1994a, b). The values of $\beta$ and $d$ were estimated using the regression of $y_{t+1} / y_{t}$ vs. frequency of healthy individuals $\left(x_{t} /\right.$ $\left.\left(x_{t}+y_{t}\right)\right)$, using all successive years for which data was available (i.e. 89-90,90-91, . . ,93-94). The change in disease frequency or the transmission coefficient was then regressed on the frequency of individuals with complete bias; regressions were weighted by the number of individuals in each segment used to estimate the bias. Neither of these regressions were significant, indicating that there was no evidence that the bias had affected the dynamics of the disease. It was also clear from studies at Section 2.1c (TABLE I) that even a very high frequency of complete bias $(98 \%)$ did not prevent disease spread; disease frequency at this site increased from $6.6 \%(\mathrm{n}=470)$ in 1991 to $12.5 \%(\mathrm{n}=645)$ in $1992\left(\chi^{2}=10.36\right.$, $\mathrm{df}=$ $1, P=0.0013)$. Unfortunately, this site was subsequently destroyed by earth-moving equipment, and the later fate of the population could not be followed.

Solopathogenicity.-Out of 252 plants inoculated with A1 single sporidial lines from completely biased individuals, 108 flowered but none were diseased. Out of 168 plants inoculated with mixtures of these same A1 lines and A2 lines (i.e., both mating types), 114 flowered and 109 of these were diseased. There was, therefore, no evidence that Al sporidial lines from biased individuals can cause disease by themselves.

Inheritance of the mating-type bias. - In the study at Kansas, 12/25 crosses between A1 lines from biased individuals and A2 lines from unbiased individuals produced disease; all were unbiased. 10/25 crosses between lines from unbiased individuals produced disease, and these too were unbiased. In the study at Duke, the five crosses between Al sporidia from biased lines and A2 sporidia from unbiased lines showed the presence of both mating types. All of the seven samples from second-generation progeny of the above crosses also showed the presence of both mating types. There was, therefore, no evidence that complete mating-type bias was heritable through the A1 mating type.

Teliospore germination.-Germinating teliospores from both biased and nonbiased samples showed four types of conjugation: (i) intersporidial conjugation between sporidia of presumably opposite mating type; (ii) sporidial-promycelial conjugation; (iii) inter-promycelial conjugation between the terminal cells of two different promycelia; and (iv) intrapromycelial conjugation between two adjacent cells within a promycelium. Observation of teliospore germi- nation in the presence of $\alpha$-tocopherol confirmed that intrapromycelial conjugation could result in the production of an infection hypha.

\section{DISCUSSION}

Our studies, in two laboratories and using several methods, have shown that many populations of the anther-smut, $U$. violacea, on $S$. alba contain high frequencies of individuals from which sporidia of only one mating type can be isolated. Complete individual-wide mating-type bias has been reported previously in single isolates of $U$. violacea from other host species (Garber et al., 1978; Garber and Ruddat, 1994), but this is the first report of this phenomenon as a consistent and widespread feature of the biology of natural populations of $U$. violacea. The occurrence of Al mating-type bias of $U$. violacea on $S$. alba has also been recently reported in Switzerland (Shykoff, pers. com.), suggesting the phenomenon may be also common in Europe. Our detailed study of the distribution of the bias within one county also showed that the frequency of the bias could vary widely from valley to valley, and that even within one valley, the pattern of distribution of biased individuals could vary over distances of less than $100 \mathrm{~m}$. Thus, in region 1 there was a clinal pattern, with A1 biased individuals (partial and complete) being common at one end of the sampling area, and A2 bias (partial and complete) being common at the other end. In region 5 , complete individual-wide bias was rare, but partial A1 bias was common. In region 6 , many individuals showed complete A1 bias, while the other individuals showed partial A2 bias.

An understanding of the mating-type bias phenomenon clearly requires knowledge of the mechanism that produces the bias. We considered four hypotheses for the mechanism: direct killing of cells of one mating type by the other (spore killers-Perkins, 1992; Nauta and Hoekstra, 1993; Raju, 1994); meiotic nondisjunction creating aneuploid or diploid sporidia that express only one mating type (Day, 1972; Caten and Day, 1977; Castle and Day, 1980, 1981); oriented segregation at meiosis favoring one mating type over the other; and, a recessive deleterious mutant closely linked to one mating type (haplolethal deficiency) resulting in a failure to isolate that mating type in the haploid phase (Fischer, 1940; Holton, 1951; Grasso, 1955; Darlington and Kiesling, 1975). The failure of the A1 mating type to transmit the bias to its progeny when mated to an A2 from an unbiased line indicates that bias is a genetic property of the $\mathrm{A} 2$ rather than the A1 mating type; this would not be the case if spore killers or oriented segregation were involved. The widespread occurrence of 
mating-type bias and absence of solopathogenicity argues against the bias being caused by meiotic nondisjunction; non-disjunction is likely to be an infrequent process and its effect would be to create sporidia that show solopathogenicity. Instead, all our evidence is consistent with the presence of a haplolethal deficiency linked to mating type; by this mechanism, we can explain the recovery of only the A1 mating type in sporidial lines and the failure of such lines to transmit the bias. In the context of the classical view of the life-cycle of $U$. violacea (Cummins and Day, 1977) where conjugation and infection follows a period of sporidial multiplication, the haplolethal allele would obviously be severely disadvantaged, since the A2 sporidia could not grow and mate. However, this does not appear to be the case, as we found no evidence that the frequency of bias is associated with a decreased disease incidence or slower rates of disease spread. Holton (1951) and Grasso (1955) also found no reduced pathogenicity in other smut species that produced sporidia of only one mating type. In Ustilago nuda which has a fourcelled promycelium, cells of opposite mating type fuse immediately and form heterokaryotic hyphae (Nielsen, 1968, 1988). Our observations of early teliospore germination showed that the formation of a conjugation tube between adjacent cells of the promycelium (intrapromycelial conjugation) was a common feature of both biased and unbiased lines. The presence of intrapromycelial conjugation has been recorded as far back as the previous century (Harper, 1899; Brefeld, 1883), but its significance has remained obscure. Such intrapromycelial conjugation would essentially "rescue" a haplolethal deficiency since there would be conjugation prior to sporidial formation, and the haplolethal would be essentially neutral (or only mildly deleterious, depending on the relative importance of sporidial growth and conjugation in the infection process). However, this still would not explain how such a haplolethal trait could spread to the high frequencies that we found in the Virginia populations. This argues that such haplolethal mutants may have compensatory, pleiotropic advantages at some other stage of the life cycle, such as at the infection process or during pathogenesis. It is possible that a component of a metabolic pathway that is essential only in the saprophytic phase may indeed be disadvantageous or costly in the parasitic phase; its loss may therefore increase the growth rate of the parasitic phase. Another effect of haplolethals may be to increase the rate of promycelial conjugation; even if the A2 cells of the promycelium cannot produce free living sporidia, they may still be able to mate with adjacent Al cells. However, whether intrapromycelial conjugation rates are higher in com- pletely biased vs. unbiased individuals remains to be determined by careful cytological observation. Intrapromycelial or early conjugation may have a selective advantage (even in the absence of bias) if it leads to a more rapid production of an infection hypha; this advantage would have trade-offs in reduced sporidial multiplication and, therefore, fewer potential conjugations at a later time.

In many microorganisms the mating-type locus (or loci) is embedded in a large nonrecombining region of the chromosome (Gillham et al., 1987), and this also appears to be the case in $U$. hordei (Bakkeren and Kronstad, 1994). In U. violacea, we have found strong linkage disequilibrium between the alleles determining allozymes of malate dehydrogenase and mating type (Antonovics et al., 1996), and a disproportionate number of RAPD variants cosegregating with mating type, suggesting substantial fixed heterozygosity in the region of the mating-type locus (Oudemans, unpubl.). It is therefore not unlikely that deleterious mutations might arise in the region of the mating-type locus. These mutants could arise in linkage disequilibrium with (and at different map distances from) either the A1 or A2 mating-type alleles, or they could vary in the degree to which they are deleterious. While in this study we found predominantly A1 bias, Garber et al. (1978) reported five cases of A1 bias and three cases of A2 bias out of a total of 22 collections of $U$. violacea from other host species. Moreover, in the present study we found very different patterns of distribution of the bias in the different regions of the study area. These divergent patterns may be the result of several different haplolethal mutants having arisen independently in the different regions of the study site. Because the environments in these regions are somewhat different (for example, the populations in region 5 are at a higher elevation than region 6), we cannot exclude the possibility that different spatial patterns of the mating-type bias are due to the haplolethal having differential effects in different environments. Contrasting nutritional requirements of the two mating types has been demonstrated in Ustilago nuda; mating type $a$ (but not $A$ ) is proline-requiring (Nielsen, $1968,1988)$. However, this environmental explanation seems unlikely given the large variation in the direction of the bias, and the marked local microheterogeneity in the frequency of bias.

Our results also indicate that unbiased individuals (i.e. fungal individuals from which both mating types could be isolated) often showed highly significant mating-type bias at the single teliospore level (TABI.E II). Single teliospore bias may result from differences in the rate of sporidial production from the promycelial cells or from the teliospore. In a colony of spor- 
idia derived after a period of exponential growth from the products of a single teliospore, the sporidium that is budded off earliest will make a disproportionate contribution to the colony. Its mating type will then be correspondingly over-represented in isolates from that colony. However, it is also possible that there are alleles that are only partially linked to mating type and which also affect growth rate of the sporidia; in this case, sporidial lines of different mating types could differ in their growth rate depending on which alleles are associated with which mating type in the parent, and on whether a crossing over event occurs between such alleles and the mating-type locus during meiosis.

The widespread occurrence of mating-type bias in natural populations may have important consequences for the mating system of the fungus. If successful infection is primarily due to a dikaryon resulting from intra-promycelium conjugation, the bias trait should be associated with a high level of selfing. Alternatively, if infection primarily results from sporidial-sporidial matings, complete individual-wide bias could be associated with greater outcrossing. The evolutionary implications of the bias trait cannot be addressed without greater knowledge of the mating and infection process, including information on which types of conjugation events lead to infection under natural conditions. Nevertheless, our study emphasizes that knowledge of which mating types are present and of their reproductive behavior in culture is not sufficient to infer the actual mating system as it operates in natural fungal populations (Ennos and Swales, 1987). Our study additionally suggests that the detailed operation of fungal mating systems may be evolutionarily quite labile and vary substantially over short distances.

\section{ACKNOWLEDGMENTS}

We wish to thank E. D. Garber for confirming our mating type determination, Bruce Nicklas for assistance with the microscopy, Angela De Sandro for help with the fungal crosses, and Michael Hood for critical comments on the manuscript. We wish to acknowledge NSF grants DEB9119409 (to HMA and PVO) and DEB-9119626 (to JA), as well as REU supplements to these awards.

\section{LITERATURE CITED}

Alexander, H. M. 1989. An experimental field study of anther-smut disease of Silene alba caused by Ustilago violacea: genotypic variation and disease incidence. Evolution 43: 835-847.

$\longrightarrow$, N. A. Slade, and R. Gomulkiewicz. 1995. A Bayesian approach to the inference of diploid genotypes using haploid genotypes. Theoret. Appl. Genet. 91: 12841287.

Altizer, S., P. H. Thrall, and J. Antonovics. 1998. Vector behavior and the transmission of anther-smut infection in Silene alba. Amer. Midl. Naturalist (In press).

Antonovics, J. 1994. The interplay of numerical and genefrequency dynamics in host-pathogen systems. Pp. 146170. In: Ecological genetics. Ed., L. Real. Princeton University Press, Princeton, New Jersey.

- - and H. M. Alexander. 1992. Epidemiology of anther-smut infection of Silene alba caused by Ustilago violacea: patterns of spore deposition in experimental populations. Proc. Roy. Soc. London, Series B 250: 157163.

—, D. Stratton, P. H. Thrall, and A. M. Jarosz. 1996. An anther-smut disease (Ustilago violacea) of fire-pink (Silene virginica): its biology and relationship to the anther-smut disease of white campion (Silene alba). Amer. Midl. Naturalist 135: 130-143.

, P. H. Thrall, A. M. Jarosz, and D. Stratton. 1994. Ecological genetics of metapopulations: the Silene-Ustilago plant-pathogen system. Pp. 146-170. In: Ecological genetics. Ed., L. Real. Princeton University Press, Princeton, New Jersey.

$\rightarrow$ Bakkeren, G., and J. W. Kronstad. 1994. Linkage of matingtype loci distinguishes bipolar from tetrapolar mating in basidiomycetous smut fungi. Proc. Natl. Acad. Sci. U. S. A. 91: 7085-7089.

$\rightarrow$ Batcho, M., and J. C. Audran. 1980. Donnes cytochimiques sur les antheres de Silene dioica parasitees par Ustilago violacea. Phytopathol. Z. 99: 9-25.

Brefeld, O. 1883. Botanische Untersuchungen uber Hefenpilze. V. Die Brandpilze I. Arthur Felix, Leipzig, Germany. $202 \mathrm{pp}$.

Castle, A. J., and A. W. Day. 1980. Diploid derivatives of Ustilago violacea with altered mating-type activity. I. Isolation and properties. Bot. Gaz. 141: 85-93.

— violacea with altered mating-type activity. II. Polyploid segregations and mechanism of origin. Bot. Gaz. 142: 279-285.

— alpha-Tocopherol as an inducer of the parasitic phase of Ustilago violacea. Phytopathology 74: 1194-1200.

Caten, C. E., and A. W. Day. 1977. Diploidy in plant pathogenic fungi. Ann. Rev. Phytopathol. 15: 295-318.

Cummins, J.E., and A. W. Day. 1977. Genetic and cell cycle analysis of a smut fungus (Ustilago violacea). Meth. Cell Biol. 15: 445-469.

Darlington, L. C., and R. L. Kiesling. 1975. A compatibilitylinked, haplo-lethal factor in race 1, Ustilago nigra (Tapke). Proc. North Dakota Acad. Sci. 27: 116-119.

Day, A. W. 1972. Dominance at a fungus mating type locus. Nature 237: 282-283.

- 1980. Competition and distribution studies of genetically marked strains of Ustilago violacea in the same host plant. Bot. Gaz. 141: 313-320.

— ysis of Ustilago violacea. Genet. Res. 14: 195-221.

$\rightarrow$ Deml, G., and F. Oberwinkler. 1983. Studies in Heterobas- 
idiomycetes, part 31. On the anther smuts of Silene vulgaris (Moench.) Garcke. Phytopathol. Z. 108: 61-70.

Ennos, R. A., and K. W. Swales. 1987. Estimation of the mating system in a fungal pathogen Crumenulopsis soraria (Karst.) Groves using isozyme markers. Heredity 59: 423-430.

$\rightarrow$ Fischer, G. W. 1940. Two cases of haplo-lethal deficiency in Ustilago bullata operative against saprophytism. Mycologia 32: 275-289.

- and Holton, C. S. 1957. Biology and control of the smut fungi. Ronald Press, New York. 622 pp.

Garber, E. D., M. L. Baird, and L. M. Weiss. 1978. Genetics of Ustilago violacea. II. Polymorphism of color and nutritional requirements of sporidia from natural populations. Bot. Gaz. 139: 261-265.

- and M. Ruddat. 1994. Genetics of Ustilago violacea. XXXII. Genetic evidence for transposable elements. Theoret. Appl. Genet. 89: 838-846.

Gillham, N. W., J. E. Boynton, A. M. Johnson, and B. D. Burkhart. 1987. Mating type linked mutations which disrupt uniparental transmission of chloroplast genes in Chlamydomonas. Genetics 115: 677-684.

Grasso, V. 1955. A haplo-lethal deficiency in Ustilago kolleri. Phytopathology 45: 521-522.

Harper, R. A. 1899. Nuclear phenomena in certain stages in the development of the smuts. Trans. Wisconsin Acad. Sci. Arts Lett. 12: 475-498.

Holton, C. S. 1951. Methods and results of studies on heterothallism and hybridization in Tilletia caries and $T$. foetida. Phytopathology 41: 511-521.

$\rightarrow$ McCauley, D. 1994. Contrasting the distribution of chloroplast DNA and allozyme polymorphism among local populations of Silene alba: implications for studies of gene flow in plants. Proc. Natl. Acad. Sci. U. S. A. 91: 8127-8131.

Nauta, M. J., and R. F. Hoekstra. 1993. Evolutionary dynamics of spore killers. Genetics 135: 923-930.
Nielsen, J. 1968. Isolation and culture of monokaryotic haplonts of Ustilago nuda, the role of proline in their metabolism, and the inoculation of barley with resynthesized dikaryons. Can. J. Bot. 46: 1193-1200.

- 1988. Ustilago spp., smuts. Advances Pl. Pathol. 6: 483-490.

Perkins, D. D. 1992. Neurospora: the organism behind the molecular revolution. Genetics 130: 687-701.

$\rightarrow$ Raju, N. B. 1994. Ascomycete spore killers: chromosomal elements that distort genetic ratios among the products of meiosis. Mycologia 86: 461-473.

Roche, B., H. M. Alexander, and A. Maltby. 1995. Dispersal and disease gradients of anther-smut infection of Silene alba at different life stages. Ecology 76:1863-1871.

Shykoff, J. A., and E. Bucheli. 1995. Pollinator visitation patterns, floral rewards and the probability of transmission of Microbotryium violaceum, a venereal disease of plants. J. Ecol. 83: 189-198.

Thrall, P. H., and J. Antonovics. 1995. Theoretical and empirical studies of metapopulations: population and genetic dynamics of the Silene-Ustilago system. Can.J. Bot. 73 (Suppl. 1): S1249-S1258.

$\longrightarrow$, A. Biere, and J. Antonovics. 1993. Plant life-history and disease susceptibility: the occurrence of Ustilago violacea on different species within the Caryophyllaceae. J. Ecol. 81: 489-498.

- - - and M. K. Uyenoyama. 1994. Frequencydependent disease transmission and the dynamics of the Silene-Ustilago host-pathogen system. Amer. Naturalist 145: 43-62.

- , and A. M. Jarosz. 1994a. Host-pathogen dynamics in experimental populations of Silene alba and Ustilago violacea I. Ecological and genetic determinants of disease spread. J. Ecol. 82: 549-559.

- and $\longrightarrow$. 1994b. Host-pathogen dynamics in experimental populations of Silene alba and Ustilago violacea II. Experimental tests of theoretical models. $J$. Ecol. 82: 561-570. 